\title{
Machine Learning with Metaheuristic Algorithms for Sustainable Water Resources Management
}

\author{
Ozgur Kisi
}

check for updates

Citation: Kisi, O. Machine Learning with Metaheuristic Algorithms for Sustainable Water Resources Management. Sustainability 2021, 13, 8596. https://doi.org/10.3390/ su13158596

Received: 22 July 2021

Accepted: 27 July 2021

Published: 2 August 2021

Publisher's Note: MDPI stays neutral with regard to jurisdictional claims in published maps and institutional affiliations.

Copyright: (C) 2021 by the author. Licensee MDPI, Basel, Switzerland. This article is an open access article distributed under the terms and conditions of the Creative Commons Attribution (CC BY) license (https:/ / creativecommons.org/licenses/by/ $4.0 /)$.
Civil Engineering Department, Ilia State University, Tbilisi 0162, Georgia; ozgur.kisi@iliauni.edu.ge

Management of available water resources needs good planning and to do this, prognostication of hydrological parameters (parameters of the hydrological cycle such as rainfall, runoff, solar radiation, groundwater, evaporation/evapotranspiration). The prediction of such phenomena is a highly non-linear issue and necessitates the usage of new mathematical methods named machine learning (ML) (Contributions 1-2). There are plenty of new ML methods and their application to the water resources area is very common these days. ML methods have several advantages, and the main ones are being able to model complex non-linear phenomena using related data without learning any physical relationship, and fast processing time to reach a solution. However, they also have some disadvantages and the main one is not having a physical basis and that it cannot be easily applied to other climatic regions without calibration/training with new data from there. Recent decades with the advancement in technology (e.g., satellite data), reaching hydrological data is much easier and this provides an opportunity to use data-driven ML tools to solve related problems. Related literature indicates that the ML methods are generally tested with point prediction with a high level of uncertainty. Determination of model uncertainty is an important issue in modelling water resources with ML methods and uncertainty analysis should be considered for an efficient decision making (Contribution 3). The use of high number of data (quantity of input variable and/or data) is very essential in developing ML models, otherwise correctly tuning hyperparameters will be very hard, especially for the advanced algorithms (Contribution 4).

This special issue involves several studies mainly covering the application of new ML methods and/or algorithms in modeling streamflow, stage-discharge relationship, flood routing, and ground water levels. Modeling streamflow as a main component of the hydrological cycle is an important issue in water resources management (Contributions 5-6). Forecasting streamflow is essential for planning and management of water resources, including early flood warning and/or flood mitigation, planning and operating reservoir, hydro-electricity production, water supply for industry or domestic use, managing droughts (Contribution 7).

The observation of water level (stage) and river discharge is very important in water resources planning and management. Adequate estimation of stage-discharge relationship is essential in designing hydraulic structures such as dams, canals, bridges and culverts. In some cases (e.g., compound and/or dynamic streams), measuring streamflow may be difficult and not so feasible. In such cases, stage-discharge rating curves (RCs) are used. However, simple regression-based RCs cannot produce discharge calculations well and therefore, ML methods have been preferred in developing stage-discharge relationship for a long time (Contribution 8).

Flood routing is essential in water resources management. Floods are catastrophic events, and they may cause several damages such as loss of life, damaged infrastructure, and other economic loses, etc. The Muskingum method (MM) is widely used for flood routing because of its easy application and accurate calculation. In the last decades, ML algorithms have been successfully used in improving MM for flood routing (Contribution 9). 
Modeling groundwater (GW) as one of the main components of the hydrological cycle is very important in water resources management. GW is a very important source for the water supply for industry, domestic use, or irrigation purposes. Accurate prediction of GW levels is essential for sustainable water resources management. ML methods or algorithms that are less costly, time-consuming, and data-intensive compared to mathematical models that uses GW dynamics are successfully used in modeling GW (Contribution 10).

The main aim of this special issue is to present various implementations of ML methods and/or metaheuristic algorithms to improve modeling and/or prediction of hydrological/water resources phenomena, which is of vital importance in water resources management. I hope that all readers of this special issue will benefit from learning about the state-of-the-art ML methods and their applications to hydrological phenomena such as streamflow, stage-discharge relationship, flood routing, and ground water level.

Institutional Review Board Statement: Not applicable.

Informed Consent Statement: Not applicable.

Acknowledgments: As the guest editor of this special issue (SI), I would like to thank all authors, reviewers, and the MDPI editorial staff for their support of this SI.

Conflicts of Interest: There is no conflict of interest in this study.

\section{List of Contributions:}

1. Ebtehaj, I.; Soltani, K.; Amiri, A.; Faramarzi, M.; Madramootoo, C.A.; Bonakdari, H. Prognostication of Shortwave Radiation Using an Improved No-Tuned Fast Machine Learning. Sustainability 2021, 13, 8009.

2. Poudel, U.; Stephen, H.; Ahmad, S. Evaluating Irrigation Performance and Water Productivity Using EEFlux ET and NDVI. Sustainability 2021, 13, 7967.

3. Nourani, V.; Paknezhad, N.J.; Tanaka, H. Prediction Interval Estimation Methods for Artificial Neural Network (ANN)-Based Modeling of the Hydro-Climatic Processes, a Review. Sustainability 2021, 13, 1633.

4. Kumar, P.; Lai, S.H.; Wong, J.K.; Mohd, N.S.; Kamal, M.R.; Afan, H.A.; Ahmed, A.N.; Sherif, M.; Sefelnasr, A.; El-Shafie, A. Review of Nitrogen Compounds Prediction in Water Bodies Using Artificial Neural Networks and Other Models. Sustainability 2020, 12, 4359.

5. Kim, S.; Alizamir, M.; Kim, N.W.; Kisi, O. Bayesian Model Averaging: A Unique Model Enhancing Forecasting Accuracy for Daily Streamflow Based on Different Antecedent Time Series. Sustainability 2020, 12, 9720.

6. He, S.; Gu, L.; Tian, J.; Deng, L.; Yin, J.; Liao, Z.; Zeng, Z.; Shen, Y.; Hui, Y. Machine Learning Improvement of Streamflow Simulation by Utilizing Remote Sensing Data and Potential Application in Guiding Reservoir Operation. Sustainability 2021, 13, 3645.

7. Adnan, R.M.; Jaafari, A.; Mohanavelu, A.; Kisi, O.; Elbeltagi, A. Novel Ensemble Forecasting of Streamflow Using Locally Weighted Learning Algorithm. Sustainability 2021, 13, 5877.

8. Kumar, M.; Kumari, A.; Kushwaha, D.P.; Kumar, P.; Malik, A.; Ali, R.; Kuriqi, A. Estimation of Daily Stage-Discharge Relationship by Using Data-Driven Techniques of a Perennial River, India. Sustainability 2020, 12, 7877.

9. Spiliotis, M.; Sordo-Ward, A.; Garrote, L. Estimation of Fuzzy Parameters in the Linear Muskingum Model with the Aid of Particle Swarm Optimization. Sustainability 2021, 13, 7152.

10. Seifi, A.; Ehteram, M.; Singh, V.P.; Mosavi, A. Modeling and Uncertainty Analysis of Groundwater Level Using Six Evolutionary Optimization Algorithms Hybridized with ANFIS, SVM, and ANN. Sustainability 2020, 12, 4023. 